\title{
Literatura e sociedade: uma leitura da representação da homoafetividade em contos brasileiros do século
}

\author{
Literature and society: an approach about the representation of homoaffectivity in short stories in the XX \\ century
}

\section{Luana Teixeira Porto}

Universidade Regional Integrada do Alto Uruguai e das Missões - URI - Frederico Westphalen - Rio Grande do Sul - Brasil

\begin{abstract}
Resumo: A literatura brasileira, especialmente e ao longo do século $X X$, passou a apresentar narrativas que tematizam de forma direta ou velada a homoafetividade. Em contos e em romances brasileiros de diferentes autores, personagens homossexuais ganharam espaço em enredos, diminuindo a sua invisibilidade; contudo, as histórias nem sempre dão voz ao homossexual, apresentando, através do narrador, vivências homoafetivas e retratando o espaço reservado na sociedade àqueles que não atendem ao padrão sexual estabelecido em contextos conservadores e patriarcais. Nesse sentido, este estudo busca analisar narrativas brasileiras curtas do século XX que abordam a temática da homossexualidade, permitindo reconhecer a relação entre a configuração do personagem homoafetivo e condicionamentos sociais. O objetivo é identificar o perfil de personagens homoafetivos em contos brasileiros e sua presença e participação nos enredos dos contos. Discutir se há, nas narrativas analisados, uma associação direta ou indireta entre homoafetividade, homofobia e exclusão social também é um dos propósitos do estudo. Para desenvolver este trabalho, tomam-se como objeto de investigação contos de diferentes autores publicados no século XX. Amparado na teoria queer, o trabalho destaca que há uma vinculação estreita entre repressão sexual e práticas de homofobia e representação literária da homoafetividade e que há pelo menos três tendências temáticas no conto que aborda a homossexualidade.
\end{abstract}

Palavras-chave: Contos brasileiros. Homofobia. Exclusão social.

\begin{abstract}
Brazilian literature, especially and throughout the twentieth century, has brought narratives that deal directly or in a veiled way the homoaffectivity. In short stories and in novels by different authors, homosexual characters are gaining ground in plots, decreasing its invisibility; however, the stories do not always give voice to the homosexual, presenting, by means of the narrator, homoaffective experiences and portraying a space reserved in society to those who do not answer the sexual pattern set both in conservative and patriarchal contexts. Thus, this study analyzes short Brazilian narratives produced in the twentieth century which deal with homosexuality, allowing recognizing the relationship between the configuration of homoaffective character and the social conditionings. The purpose is to identify the profile of homosexual characters in Brazilian short stories and their presence and participation in the plots of the stories. Also, one of the goals here is to discuss whether there is or there is not, in such narratives, a direct or an indirect association between homoaffectivity, homophobia, and social exclusion. To develop this proposal, short stories published in the twentieth century by different authors were taken into account. Departing from the queer theory, this work highlights that there is a close relationship between sexual repression and homophobia and the so-called literary representation of homoaffectivity and that there are at least three thematic trends in the short stories with deals with homosexuality.
\end{abstract}

Keywords: Metaphor. Brazilian short stories. Homophobia. Social exclusion. 


\section{Introdução}

Como representação social, a literatura tem (des)construído imagens de determinados grupos sociais, como os de mulheres e pobres, disponibilizado espaços para a presença de vozes historicamente silenciadas, dentre as quais as de etnias afro-brasileiras e indígenas, e ainda oportunizado que temas caros à discussão no Brasil sejam tratados de forma mais livre e ampla nos textos literários em prosa e verso, a exemplo da homossexualidade. Este tema, de um modo geral, quando tratado no espaço literário, permite "ler" o Brasil não como um lugar de liberdade sexual ou paraíso, mas como um cenário em que ainda imperam o preconceito a sexualidades não hegemônicas e práticas de homofobia. Isso certamente contribui para reiterar a percepção de que aqui há forte repressão sexual e uma aparente (ou falsa?) aceitação da homoafetividade.

Talvez cientes desse dado contextual, diferentes escritores da literatura brasileira, ao longo do século $X X^{1}$, passaram a apresentar narrativas que tematizam de forma direta ou velada a homoafetividade. Em diversos contos e romances, personagens homossexuais ganharam espaço em enredos, diminuindo a sua invisibilidade; contudo, as histórias nem sempre dão voz ao sujeito homossexual, apresentando, através do discurso do narrador, vivências homoafetivas e o espaço reservado na sociedade àqueles que não atendem ao padrão sexual estabelecido em contextos conservadores e patriarcais.

Nesse sentido, este estudo busca analisar narrativas brasileiras curtas do século $X X$ que abordam a temática da homossexualidade, permitindo reconhecer a relação entre a configuração do

\footnotetext{
1 Embora seja observada no século $X X$ a presença mais constante da temática da homossexualidade na literatura brasileira, poemas de Gregório de Matos, no século XVII, já faziam alusão à homossexualidade, associando sexualidade e valores religiosos e morais, assim como no século XIX romances, como O Ateneu, de Raul Pompeia, e Bom-crioulo, de Adolfo Caminha, apresentaram personagens com comportamentos homossexuais, mesmo que o tema central das narrativas não fosse a identidade sexual dos personagens. Dessa forma, a homossexualidade texto literário não é um tema novo em nossa literatura no século $X X$.
}

personagem homoafetivo e condicionamentos sociais. O objetivo é identificar o perfil de personagens homoafetivos em contos brasileiros e sua presença e participação nos enredos dos contos. Discutir se há, nas narrativas analisadas, uma associação direta ou indireta entre homoafetividade, homofobia e exclusão social também é um dos propósitos do estudo. Para desenvolver este trabalho, tomam-se como objeto de investigação contos publicados por diferentes autores no século $X X$.

\section{Literatura, sociedade e homotextualidade}

Em uma sociedade fundada no ideal do patriarcado e sustentada no heterossexismo compulsório, como se configura o contexto brasileiro, a homossexualidade é uma orientação sexual questionada e condenada. Motivo de piadas, deboche, discriminação e exclusão social, sujeitos homossexuais são ainda alvos de violência física e posturas homofóbicas. E essa vivência condiciona, muitas vezes, o sujeito à marginalidade $e$ à marginalização e a adoção de seu status como "excêntrico". Sobre este termo, Linda Hutcheon (1991) explica: "Quando o centro começa a dar lugar às margens, quando a universalidade totalizante começa a desconstruir a si mesma, a complexidade das contradições que existem dentro das convenções como, por exemplo, as de gênero - começam a ficar visíveis" e, então, opondo-se a uma "homogeinização cultural", surgem grupos que destoam da "fórmula generalizante" em relação a "gênero, classe, raça, identidade étnica, preferência sexual, educação, função social, etc." e afirmam sua "identidade por meio da diferença e da especificidade" (p. 86), caracterizando-se como "ex-cêntricos", ou seja, grupo de sujeitos "silenciosos, definidos por diferenças de raça, sexo, orientação sexual, identidade étnica, status pátrio, classe" (p. 89).

Essa condição ex-cêntrica tem sido problematizada na literatura brasileira tanto em prosa quanto em verso. Por isso, a homotextualidade, como configuração literária específica para tratar da representação da homossexualidade no texto literário, 
precisa ser estudada. Entendemos que o termo "homotextualidade" busca especificar o texto literário que trata tematicamente da sexualidade ex-cêntrica no sentido de reconhecer que alguns textos têm como mote central a problematização da sexualidade, assumindo engajamento na luta pela liberdade sexual e procurando dar voz aos sujeitos homossexuais ou aos outros que os veem e contam suas histórias. Nessa perspectiva, importa registrar que a adoção dessa terminologia não implica dizer que existem textos literários que manifestam estilos, gêneros ou recursos estéticos e linguísticos diferentes quando abordam a homoafetividade e tampouco que esses textos sejam agrupados numa literatura tecnicamente especificada, como "literatura gay" ou "literatura homoerótica". O uso da expressão homotextualidade indica apenas a existência de textos literários que tratam de forma mais direta a homossexualidade, dando voz a quem vivencia e a quem a observa.

Compartilhamos, seguindo essa linha de raciocínio, a concepção de homotextualidade definida por José Ismael Gutiérrez, para quem a homotextualidade não se configura como novo método crítico, mas como um "suplemento [...] de outras clases de teoría literaria y, em tal sentido, acomete uma ruptura de la gran liberación de la sexualidad de la minorías" (2007, p. 26). O homotexto, então, marcaria uma oposição entre um eu que expressa sua perspectiva homossexual e um outro, que a observa, avalia e também condena. $O$ discurso do eu seria, ainda, um discurso de resistência à heteronormatividade, que, na cultura latino-americana, consolida-se como regra.

David William Foster explica que a heteronormatividade é a "urgencia imperativa de ser heterosexual y de abogar em todo momento y a toda costa pro La primacía de lo heterosexual (entiéndase lo que entendiere por este término)." (2001, p. 49). Não assumir-se como heterossexual, sendo homossexual, implica resistir à norma, o que, por sua vez, demanda questionamento da própria norma e uma imagem do sujeito desviante como um sujeito "estranho" em seu meio, mas disposto a tornar legítima a sexualidade não legitimada socialmente.
Esse estranhamento conduz à concepção teórica do queer.

O termo queer, ainda sem uma tradução específica na língua portuguesa, foi incorporado a uma teorização surgida no campo da Filosofia e Estudos Culturais, nos anos 1980, nos Estados Unidos, para questionar 0 heterossexismo compulsório e insultos e acusações contra homossexuais ${ }^{2}$. Portanto, a teoria queer não propôs o combate à heterossexualidade e sim ao ritual social de imposição da heterossexualidade como norma de comportamento sexual. Segundo explica Lizandro Carlos Calegari, a teoria queer não se restringe à abordagem de questões sexuais ou de desejos sexuais, "mas também um amplo quadro de dinâmicas sociais ${ }^{3}$ (...) que é homologamente correlato à sexualidade enquanto discurso dominante na sociedade contemporânea." (2007, p. 118). Para o autor, a teoria queer contribui para um "questionamento produtivo não apenas da construção cultural da sexualidade, mas da própria cultura, tal como baseada numa negação das relações homoeróticas". (2007, p. 118).

Nessa perspectiva, analisando-se a prosa brasileira, em especial a narrativa curta, importa observar em que medida escritores têm demonstrado uma postura "cómplice com el proyecto de la heternormatividad" e como autores subvertem a lógica imperativa e discutem a legitimidade da heternormatividade (FOSTER, 2001). Como nos propomos estudar o conto brasileiro do século $\mathrm{XX}$, é oportuno destacar que nem sempre o discurso do eu homossexual se manifesta no texto literário, já que a estratégia de tratamento da homoafetividade muitas vezes se concretiza via discurso de um narrador observador, apenas algumas vezes comprometido com uma visão crítica sobre o que relata e fortemente inclinado a tratar o personagem homossexual como um sujeito ambíguo, sem identidade homossexual definida, ou sem voz. Por isso, este estudo busca analisar narrativas brasileiras curtas do século $\mathrm{XX}$

2 Teresa de Lauretis e Judith Butler são consideradas fundadoras dessa teoria.

3 Formas de se vestir ou aparência física, classe social e profissão são apontados pelo autor como exemplos dessas dinâmicas sociais. 
que abordam a temática da homossexualidade, permitindo reconhecer a relação entre configuração do personagem homoafetivo e do narrador $e$ condicionamentos sociais.

\section{Conto brasileiro do século XX: da homoafetividade sugerida à homofobia declarada}

Cientes de uma vivência à margem do sujeito homoafetivo e acompanhando o movimento social no país em relação à rejeição da homossexualidade, contistas brasileiros têm criado histórias sobre homoafetividade sem, contudo, tratar sempre do assunto abertamente. Há, assim, narradores que insinuam relações homoafetivas entre personagens e outros que tornam inexistentes as vozes homossexuais nas histórias, contribuindo para um silenciamento da palavra e da perspectiva do sujeito com inclinação homoafetiva. Há ainda caracterização imprecisa ou ambígua de personagens homossexuais nos textos ou identidade homossexual definida, mesmo que neste segundo caso as narrativas curtas sejam menos numerosas e o resultado final das tramas seja sombrio em relação à sexualidade.

Ao observarmos contos publicados ao longo do século XX no Brasil, mesmo que não tenhamos um registro quantitativo preciso das narrativas nem um mapeamento exato de obras e autores que abordam a homoafetividade, é possível encontrar pelo menos três tendências de abordagem da homossexualidade: homoafetividade sugerida, homoafetividade revelada, homoafetividade reprimida/condenada. A primeira tendência refere-se a narrativas que tratam da homoafetividade de forma velada, mais sugerindo o envolvimento amoroso e/ou sexual entre sujeitos do mesmo gênero do que registrando a relação homoafetiva. Nesse caso, o narrador, através de seu discurso, assume um papel fundamental: sugerir em vez de dizer o encontro amoroso e/ou sexual entre dois homens ou duas mulheres, havendo um espaço reduzido ou inexistente para a voz do sujeito homossexual. Já a segunda tendência engloba narrativas que optam pelo registro claro da experiência homoafetiva, ora acentuando a vivência do amor, ora a dificuldade de concretização amorosa entre parceiros, ora destacando o prazer da sexualidade ex-cêntrica. A voz dessa expressão amorosa e/ou sexual pode ser concretizada tanto através do discurso do narrador quanto do personagem. A terceira tendência refere-se a narrativas em que homoafetividade é condenada pelo eu ou outro, ou seja, tanto pelo sujeito homossexual que se autorreprime pela vivência contrária à heteronormatividade quanto pelos outros, a sociedade representada na história através do discurso de narrador ou personagem, que, em atenção a padrões de comportamento legitimados socialmente, impõem resistência ao prazer e ao amor na relação homossexual.

Publicado na primeira metade do século passado, o conto "Frederico Paciência", de Mário de Andrade, é uma narrativa expressiva da primeira tendência. $\mathrm{O}$ conto, pertencente à coletânea Contos novos, lançada postumamente em 1947, é narrado em primeira pessoa por Juca, que também é narrador em outras histórias da obra. Neste conto, Juca, já maduro e adulto, relata sua admiração e amor pueril por Frederico Paciência, seu então colega de escola, por quem ele registra ter sentido extremo afeto e apreço, "simpatia deslumbrada", embora apenas vivida uma amizade profunda.

No decorrer da narração, Juca manifesta ter havido entre ele e Frederico Paciência um envolvimento afetivo que não passou despercebido pelos outros, embora os dois nunca manifestassem abertamente seus amores e encontros. É nesse momento que o tom sugestivo da narrativa acerca da homoafetividade surge intensamente, pois, embora Juca registre a rejeição dos outros pelos dois na escola, não revela a sua homossexualidade, optando por referir-se a uma "amizade agressiva" existente entre os dois, sobre a qual "não faltaram bocas de serpentes" e atitudes coercitivas que culminaram em briga de Frederico Paciência com colegas da escola quando este foi vítima de agressão verbal e insinuação clara sobre sua relação com Juca. 
Não só Frederico, mas também Juca rebate as maledicências e "calúnias" sobre a suposta homossexualidade, como diz o narrador, tentando convencer a si mesmos de que era apenas amizade 0 que um sentia pelo outro. Todavia, os dois não conseguem disfarçar, depois de uma briga na escola com colegas acusadores do "desvio" de comportamento, seu afeto e beijam-se no rosto "calorosamente e reprimem o ato, cientes da separação e afastam-se", temendo maiores imbróglios. Mas guardam a "amizade eterna" e passam a "tomar mais cuidado" com a exterioridade da aproximação, seguindo mais tarde suas vidas em locais diferentes e em carreiras profissionais diversas a partir da morte do pai de Frederico, o que o obriga a mudar de cidade. O final do conto retrata a vida de Frederico longe de Juca, cada um vivendo seus destinos afastados.

O conto de Mário de Andrade explora a dificuldade de concretização amorosa e sexual de dois sujeitos do mesmo sexo em uma sociedade discriminatória e conservadora, além de registrar o conflito existencial diante da suposta descoberta da homossexualidade em rapazes jovens, ainda não iniciados nos prazeres sexuais, e a idealização do objeto de amor que retoma um traço do romantismo oitocentista, neste conto manifestada pela admiração plena e acrítica de Juca por Frederico. Referimo-nos à suposta homossexualidade porque a narrativa não explicita a orientação sexual dos dois e deixa nas entrelinhas e nas descrições dos encontros, olhares e gestos a indicação da relação homoafetiva, o que acena para o caráter sugestivo de narrativas sobre homossexualidade que englobam a primeira tendência anteriormente comentada. Esse caráter ambíguo do texto materializa-se tanto na voz do narrador quanto na dos personagens.

Considerando que o conto de Andrade foi publicado na primeira metade do século $X X$, quando o patriarcado se mostrava mais forte do que é hoje no Brasil, é natural compreender a dificuldade de registro verbal da relação homoafetiva, que certamente seria um "contrassenso" ao discurso hegemônico da sociedade conservadora e patriarcal brasileira, que pregava a ideia de família constituída por marido, mulher e filhos através do matrimônio e a relação sexual entre homem e mulher como meio para procriação. Dessa forma, havia uma deslegitimação social para o "desvio" a essa regra. Mesmo sendo Mario de Andrade um líder vanguardista na literatura, seu espírito inovador, revolucionário e contrário a normas (no caso aqui, fazemos referência a seu projeto modernista dos anos 1920), em sua narrativa sobre (homo)afetividade não se evidencia. E uma razão para isso pode estar relacionada a dados da conjuntura social. Nesse período, ainda ressoavam no país teses científicas do século XIX que tratavam o homossexual como doente e portador de anomalia física, a quem castigos ou punições físicas deveriam ser impostos para a "cura" da patologia. Em contexto assim, seria complexo (e também perigoso) construir defesa pública, via literatura, do comportamento homossexual. Seria mais oportuno criar uma ambientação narrativa mais sugestiva e capaz de sensibilizar o leitor para o amor ingênuo e descompromissado sexualmente entre dois homens. $E$ isso Mario de Andrade fez com maestria na narrativa, incitando o leitor de seu tempo e de agora a observar a legitimidade dos sentimentos afetivos como algo não atrelado à identidade sexual.

A segunda tendência do conto, que recobre narrativas em que a homossexualidade é revelada, pode ser exemplificada por uma história de Caio Fernando Abreu. "Anotações sobre um amor urbano", do livro Ovelhas negras, de 1995, é um conto em que a relação homossexual é explicitada pelo discurso do narrador e personagens. A história inicia-se com a citação de um fragmento da obra Lucas, Naim, de Hilda Hilst, o qual se constituiu numa declaração de amor traduzida na comparação entre o sentimento de um sujeito e o amor de uma flor e das serpentes por seus pares. O amor extremo expresso na citação bibliográfica é o pano de fundo de um enredo cujo cenário é uma cidade não identificada, movimentada e também contaminada pela doença, pelo vírus da AIDS. Um lugar onde viver o amor é correr risco, conforme anuncia o narrador-personagem do conto. 
Nesse conto, um discurso subjetivo e emotivo marca a narração em primeira pessoa, realizada por um homem que se dirige a outro homem fazendo a ele declarações de amor e convites para a concretização de laços de afeto. Desde o início, o narrador-personagem revela a sua condição de ser homossexual. Como 0 interlocutor de suas declarações amorosas não responde, apenas sorri, o narrador continua a argumentar a favor do envolvimento entre os dois, aproxima-se mais do companheiro, toca-o, beija-o, na tentativa de fazer com que o contato físico incite o afetivo. Para o narrador-personagem, poder se relacionar com o homem a quem se declara é uma forma de enfrentar a vida numa cidade atribulada, como nos grandes centros, repleta de engarrafamento de trânsito, pessoas enlouquecidas, paranoia à solta: "[a] cidade está louca, você sabe. A cidade está doente, você sabe. A cidade está podre, você sabe. Como posso gostar limpo de você no meio desse doente podre louco? [...] Tenho pressa, não podemos perder tempo. (ABREU, 2002, p. 188).

O narrador-personagem deixa clara a urgência da decisão do outro, visto ser o tempo um inimigo para a concretização do encontro, especialmente quando se está vivendo numa cidade doente, e também porque está contaminado pelo vírus da Aids. Contudo, essa realização amorosa e sexual fica dificultada, pois, enquanto o narrador-personagem quer viver o relacionamento mesmo correndo o risco da morte, o companheiro mostra-se mais temeroso. A sinalização do "medo" e a certeza dos "riscos" de um "desregramento" moral e sexual condicionam a desestruturação e a insegurança do companheiro, cuja identidade é obscura e cuja postura mostra-se movediça, pois, ao mesmo tempo em que o companheiro deixa transparecer o mesmo desejo de viver a relação, recua ao sentir culpa por um ato "anormal". A anormalidade da relação é considerada, no contexto do texto, segundo a ditadura social do relacionamento homem/mulher, numa oposição ao encontro homoafetivo. O companheiro, consciente da "transgressão" sexual numa sociedade que valoriza a heterossexualidade, parece não se sentir seguro sobre a sua própria identidade sexual, ao contrário do outro, que quer viver o risco: "Eu quero o risco, não digo. Nem que seja a morte" (ABREU, 2002, p. 189).

"Anotações sobre um amor urbano" retrata a vivência da relação homoafetiva sob a ameaça da doença, sinalizando que a experiência do prazer e do amor, embora possa não ter continuidade pela ação agressiva do vírus, singulariza os sujeitos que não se deixam abalar pelo medo da morte e que não hesitam em assumir sua identidade sexual. A revelação da voz de personagens homossexuais, no conto, mostra que há um interesse do escritor em tratar de forma livre e sem rodeios a homoafetividade, fugindo de uma caracterização estereotipada de gays e de uma negação da homossexualidade, que é abordada no conto como uma dentre várias possíveis formas de amor e prazer. Sabendo que o texto foi publicado no final dos anos 1990, quando havia o reflexo de movimento anterior (da década de 1960) de libertação sexual e os estudos de gênero originados nos Estados Unidos já estavam ecoando no Brasil de forma mais sistematizada, não é estranho reconhecermos vozes explícitas da homossexualidade na narrativa. Nesta história, chama atenção também a alusão à Aids como um "risco" do amor entre sujeitos do mesmo sexo, clara leitura de um contexto em que o vírus impunha grande temor pela ausência de tratamento efetivo para a doença.

Esses dados contextuais são importantes para compreender conjuntura de produção do texto; entretanto, não podemos estabelecer uma relação de causa e efeito direta entre contexto social mais democrático em relação à sexualidade e abordagem mais aberta da homossexualidade na literatura. Há de ser observado também o papel do escritor e seu engajamento em temas sociais. Caio Fernando Abreu escreveu inúmeras narrativas (contos e romances) em que a homossexualidade é tratada de forma poética e crítica. Mesmo que rechacemos de forma veemente o rótulo de literatura gay acerca dos seus textos e a imagem do escritor como um autor do homoerotismo, é inegável haver na sua obra uma preocupação em problematizar a sexualidade e 
colocá-la como objeto de apreciação e reflexão ao leitor, numa tentativa de unir vida literária e vida social.

E é por considerar essa vertente da obra do escritor que elegemos outro conto seu para ilustrar a terceira tendência da narrativa curta, a que aborda a homoafetividade condenada. Em Morangos mofados, Abreu apresenta o conto "Terça-feira gorda", em que narra explicitamente a relação homoafetiva entre dois homens numa festa de carnaval, evento típico brasileiro em que as liberdades são defendidas e em que o uso de máscaras e fantasias é o meio adotado para representar papeis sociais escolhidos pelos participantes da festa carnavalesca.

A narrativa, contada em primeira pessoa através de um discurso objetivo por um dos personagens protagonistas, revela a voz do sujeito homossexual que busca viver seus prazeres de forma livre e sem culpa, o que acentua a ideia de sexualidade como algo que não pode ficar preso a identidades fixas e a concepção de que a vivência da sexualidade independe de dissociação de gênero dos sujeitos envolvidos:

$\mathrm{Na}$ minha frente, ficamos nos olhando. Eu também dançava agora, acompanhando o movimento dele. Assim: quadris, coxas, pés, onda que desce, olhar para baixo, voltando pela cintura até os ombros, onda que sobe, então sacudir os cabelos molhados, levantar a cabeça e encarar sorrindo. Ele encostou o peito suado no meu. Tínhamos pelos, os dois. Os pelos molhados se misturavam. Ele estendeu a mão aberta, passou no meu rosto, falou qualquer coisa. O quê, perguntei. Você é gostoso, ele disse. E não parecia bicha nem nada: apenas um corpo que por acaso era de homem gostando de outro corpo, o meu, que por acaso era de homem também. Eu estendi a mão aberta, passei no rosto dele, falei qualquer coisa. O quê, perguntou. Você é gostoso, eu disse. Eu era apenas um corpo que por acaso era de homem gostando de outro corpo, o dele, que por acaso era de homem também. (ABREU, 1995, p. 51)

"Terça-feira gorda" ainda acrescenta um dado importante acerca das histórias literárias sobre homossexualidade: a presença da repressão sexual e de práticas de homofobia como dados pertencentes à sociedade brasileira. Assim que são vistos juntos pelos outros participantes da festa, os dois homens são vítimas de piadas e insultos verbais e passam a ser perseguidos; na fuga em direção à praia, são alcançados por populares, que os espancam física e moralmente. Um deles consegue fugir, o outro, não. A cena final do conto é o desfecho trágico da morte daquele que ousou a viver a liberdade sexual no Carnaval, uma morte vista pelo próprio companheiro como "a queda lenta de um figo muito maduro, até esborrachar-se contra o chão em mil pedaços sangrentos. (ABREU, 1995, p. 53). A metáfora da fruta que se estilhaça no chão, de um lado, expõe a violência de uma política da sexualidade, a qual se manifesta contrária às relações homoeróticas, condenando os sujeitos homoafetivos à exclusão social e morte; de outro, sinaliza a dualidade da sociedade brasileira que, ao mesmo tempo em que celebra o Momo e a subversão característica do Carnaval desde o Renascimento ${ }^{4}$, permite a repressão ao "desregramento" e a prática de violência como meio de "correção" desse "desvio".

Há, no conto, a partir dessa problematização da homossexualidade no contexto social brasileiro, uma inclinação para uma literatura de denúncia e questionamento do heterossexismo compulsório que caracteriza sociedades de base patriarcal. A pratica do heterossexismo compulsório que resulta em práticas de repressão sexual sinaliza a existência de uma sociedade homofóbica, não preparada para a liberdade sexual e ainda afeita a regras fixas de identidade sexual. Além disso, a narrativa destaca a necessidade de uma subversão de escrita no sentido de não omitir o desejo homoerótico na narrativa e explorar diferentes níveis de linguagem para composição de cenários e vivências afetivas. Se há

\footnotetext{
4 Segundo Moacyr Scliar, o Carnaval no Renascimento era compreendido como uma "válvula de escape" fundamental para a interrupção da agressividade e para uma liberação geral dos costumes, pois os mascarados podiam insultar pessoas e criticar autoridades. Para o pesquisador, o Carnaval também aludia a sexo e à carnalidade - a palavra carnaval vem de carne -, o que intensificada o culto ao corpo e à sexualidade. Todos esses traços faziam dessa festa popular um "símbolo da subversão": "Tudo no Carnaval contribui para essa ideia de subversão. Assim a máscara é expressão de metamorfose, de violação dos limites, de ridicularização: um simbolismo inesgotável. O grotesco, no Carnaval, emergia diretamente da cultura popular." (2003, p. 110-111). Os elementos caracterizadores do Carnaval no Renascimento podem também ser estendidos ao Carnaval moderno no sentido que ele continua a ser visto como "símbolo da subversão", do desregramento.
} 
uma política de repressão sexual, como indica o conto, há de haver também uma política de subversão literária, caracterizada pela resistência ao discurso hegemônico em relação à sexualidade e ao silenciamento de vozes representativas da homoafetividade.

\section{Considerações finais}

As narrativas ilustram três tendências de abordagem da homossexualidade no conto brasileiro do século $X X$ e, mesmo que essas tendências não estejam esgotadas, tendo-se em vista o conjunto da contística desse período, e que seja possível adicionar perspectivas narrativas em relação ao tema, a identificação de formas de apresentação de histórias sobre homoafetividade ajuda a compreender um pouco a relação entre história da homossexualidade no Brasil e seus reflexos na construção literária. Assim como nos estudos literários, em outros campos do saber a homossexualidade há pouco tempo vem sendo debatida. Podemos notar que a história da homossexualidade no Brasil começou a ser abordada em estudos sociológicos e antropológicos apenas nos anos 1970, com trabalhos do pesquisador Peter Fry, que investigou o comportamento sexual de homens que viviam no Pará e assim iluminou novas gerações de estudiosos a tratar do tema. $\mathrm{Na}$ área dos estudos literários, ainda há muito a se investigar sobre a presença de vozes ficcionais e autores homossexuais na literatura desde seu nascimento, considerando diferentes gêneros literários e tendências artísticas.

Cientes dessas lacunas nos estudos e com interesse em desvendar a literatura que aborda a homoafetividade, acreditamos que começar a traçar tendências em narrativas curtas pode ser um meio profícuo para compreender as relações entre literatura, sociedade e homossexualidade em nosso país. Por isso, acreditamos ser necessário também um olhar comparatista sobre os contos examinados. Nas narrativas analisadas, é possível também estabelecer uma associação entre homoafetividade e exclusão social, seja esta resultado da ação dos outros, seja da percepção do eu em relação à vivência do amor e do prazer entre sujeitos do mesmo sexo. O conto "Frederico Paciência", ao caracterizar personagens de forma ambígua, mostra o quanto o eu se reprime e busca se confortar com uma amizade verdadeira, fugindo das possibilidades de um envolvimento mais sério com outra pessoa e sinaliza também quanto o outro observa atentamente os deslocamentos de eus supostamente inclinados à homossexualidade e age para conter impulsos sexuais desobedientes à moral conservadora. A narrativa "Anotações de um Amor urbano", que traz personagens claramente assumidos como homossexuais, também evidencia a luta de um eu contra seus próprios desejos homossexuais e vivência do amor e do prazer com risco e olhar dos outros sobre a homossexualidade. A história de "Terça-feira gorda", que apresenta de forma direta a homossexualidade dos personagens, revela a certeza de dois eus diante de sua identidade sexual e problematiza a postura repressiva e violenta dos outros diante da homossexualidade e ainda acrescenta a hipocrisia social ao contextualizar desregramento e liberdade no Carnaval.

Observadas de forma comparada, as três narrativas apresentam uma coordenada em comum: podem ser lidas como histórias de registro da dificuldade de revelação ou vivência da condição homossexual em contextos que deveriam ser mais democráticos e menos discriminatórios em relação à sexualidade. Nessa perspectiva, para encerrar este artigo, vale recorrer ao que David Foster declarou, ao alertar sobre a necessidade de se reconhecerem outras formas legítimas de prazer:

Se contempla una reconsideración del cuerpo humano, urgida a tanto por la necesidad de combatir la primacía obsesiva de la heterosexualidad en lo genital como única sede del placer legítimo y como metonimia rectora para establecer la identidad del individuo, como por la propuesta creciente de propiciar la erotización total del cuerpo. (FOSTER, 2000, p. 17) 


\section{Referências}

ABREU, Caio Fernando. Ovelhas negras. Porto Alegre: L \& PM, 2002.

Morangos mofados. 9. ed. São Paulo: Companhia das Letras, 1995.

ANDRADE, Mario de. Contos Novos. São Paulo: Klick Editora, 1997.

CALEGARI, Lizandro Carlos. O homoerotismo em Caio Fernando Abreu: a perspectiva queer em Morangos mofados. Luso-Brazilian Review, University of Wisconsin, Estados Unidos da América, v. 4, n. 2, p. 117-133, 2007.

FOSTER, David William. Consideraciones sobre el estudio de la heteronormatividad en la literatura latinoamericana. Letras, n. 22, p. 49-53, jun/2001. Disponível em: <http://cascavel.ufsm.br/revistas/ojs2.2.2/index.php/letras/article/view/11823/7251>. Acesso em: 10 ago. 2015.

GUTIÉRREZ, José Ismael Gutiérrez. Reinaldo Arenas: entre el placer y el infierno. Dover: Cursak Books, 2007.

HUTCHEON, Linda. Poética do pós-modernismo: história, teoria, ficção. Trad. Ricardo Cruz. Rio de Janeiro: Imago, 1991.

SCLIAR, Moacyr. Saturno nos trópicos - a melancolia europeia chega ao Brasil. São Paulo: Companhia das Letras, 2003. 